Claremont Colleges

Scholarship@ Claremont

CGU Faculty Publications and Research

CGU Faculty Scholarship

$1-1-2006$

\title{
Word Association Tests of Associative Memory and Implicit Processes: Theoretical and Assessment Issues
}

\author{
Alan W. Stacy \\ Claremont Graduate University \\ Susan L. Ames \\ Claremont Graduate University \\ Jerry L. Grenard \\ Claremont Graduate University
}

\section{Recommended Citation}

Stacy, A.W., Ames, S.L., \& Grenard, J.L. (2006). Word Association Tests of Associative Memory and Implicit Processes: Theoretical and Assessment Issues. In R.W. Wiers \& A.W. Stacy, Eds. Handbook of Implicit Cognition and Addiction. Thousand Oaks, CA: SAGE.

This Book Chapter is brought to you for free and open access by the CGU Faculty Scholarship at Scholarship @ Claremont. It has been accepted for inclusion in CGU Faculty Publications and Research by an authorized administrator of Scholarship @ Claremont. For more information, please contact scholarship@cuc.claremont.edu. 


\title{
Word Association Tests of Associative Memory and Implicit Processes: Theoretical and Assessment Issues
}

\author{
Alan W. Stacy, Susan L. Ames, \\ AND JERRY L. GRENARD
}

\begin{abstract}
Word association is one of the most commonly used measures of association in cognitive science. These tests have been used to infer association parameters in normative studies, to derive cues and primes used in diverse paradigms (semantic priming, cued recall, illusory memory), to test implicit memory in experimental studies, and to suggest the operation of implicit processes in nonexperimental work. This chapter briefly outlines some of the historical routes and current controversies about association and summarizes basic cognitive research applying associative tests. The authors then describe benefits and limitations of the tests, as well as implications for theory and interventions on drug use.
\end{abstract}

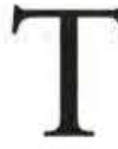
his chapter briefly outlines some of the historical routes of word association and then summarizes several of the major streams of basic cognitive research revealing the value of these tests. We delineate several current controversies from this basic research and suggest why they are critical for understanding drug-related cognitions and behavior. We then address benefits, limitations, and further implications of the tests.

\section{A BRIEF HISTORY OF WORD ASSOCIATION}

The concept of association can be traced back to Aristotle and was not refined substantially until the effort of the British empiricists (Dawson, 2004). Some of Aristotle's primary concepts such as contiguity, similarity, and sequence effects anticipated a variety of associationist and connectionist models of the last

AUTHOR'S NOTE: This chapter was supported by a grant from the National Institute on Drug Abuse, DA16094. 
century and today. In the 19th century, John Mill's philosophical work on association was a precursor of contemporary notions that associations can come together in new constellations that have emergent properties. William James (1913) elaborated on the importance of cognitive sequences, suggesting that one brain state leads to activity of another state that has been previously associated with the first. This idea and other concepts from James (e.g., pattern association) anticipated a number of subsequent developments in connectionist models (Dawson, 2004) that have been viewed as substantial elaborations or expansions of earlier associationism evolved to embrace emergent properties, distributed representations, nonlinear activation rules, and other innovations (Bechtel \& Abrahamsen, 2002). As revealed below, association is still alive and well in contemporary cognitive research.

Word association has become one of the primary methods used to infer association in cognitive research, whether cast in terms of associative or connectionist models. The first research the authors found using this method was conducted by Francis Galton in 1879 (Crovitz, 1970). Although he is better known for his interest in evolution and heredity, he also studied the association of ideas in thought (Boring, 1950). Galton's results influenced the subsequent work of Jung (1910) as well as Wundt and Catell (Cattell \& Bryant, 1889; Thorne \& Henley, 2001).

Freud began developing his method of free association for psychoanalysis in $\mathbf{1 8 9 2}$ and might have been influenced by Galton (Thorne \& Henley, 2001), but the method does not normally use word association tests. Instead, the patient is expected to talk freely about a symptom or a dream (Freud, 1995). On the other hand, free association as it is used in studies of verbal behavior and cognition implies free word association, in which the participant is instructed to respond with the first word or series of words that come to mind when presented with a word or phrase as a stimulus (Woodworth, 1921). In a controlled word association test, the participant is instructed to respond with words from a certain category (e.g., name animals that are mammals; Woodworth, 1921).

Word association was used later in the last century by both behaviorists (e.g., Cook \& Skinner, 1939) and cognitive psychologists (e.g., Cramer, 1968; Deese, 1959a). Some of this research has had major influences on contemporary approaches. For example, Deese's (1959b) research has been substantially extended in recent studies on illusory memory, Underwood's (1965) concept of implicit associative response has influenced contemporary theories, and Noble's (1952) work on continuous association influenced later research on associative structures relevant to culture and drug use.

\section{CONTEMPORARY COGNITIVE PARADIGMS REVEALING THE VALUE OF WORD ASSOCIATION}

Although a few researchers have reported on the reliability of word association measures or norms (e.g., Preece, 1978; Stacy et al., 1993; Szalay et al., 1970), most cognitive research on this task provides evidence of predictive value rather than psychometric information. Findings from contemporary paradigms have revealed that word association norms predict cognitive responses that are often attributed to implicit or automatic processes. These findings may mirror at least some of the implicit processes that are engaged when behavior choices, such as drug use, are made. Many of these paradigms attempt to uncover processes that occur spontaneously, without the need for extensive deliberation, conscious recollection of events, or the conscious weighing of pros and cons. 


\section{Semantic Priming}

In semantic priming, responses to a target stimulus (e.g., the word cat) are facilitated (i.e., speeded up compared to some baseline) if the target is preceded by a related prime word (e.g., dog). The most common procedure is lexical decision, where targets are either words or nonword letter strings (e.g., atcs) and primes are related words, unrelated or neutral words, or other variations (e.g., nonword letter strings). The participant's task is to indicate whether the target stimulus is a word or not, usually on two computer keys labeled yes or no. Another commonly used semantic priming paradigm is word naming (pronunciation), which is similar in presentation of prime/target pairs but requires naming the target word out loud rather than lexical (word/nonword) decision. In both lexical decision and naming, a common finding is that reaction times for decisions or naming are decreased if a target is preceded by a related prime compared to a neutral prime, although facilitation effects depend on the specific type of prime-target relation (Hutchison, 2003; Neely, 1991). Semantic priming has been used to infer a variety of automatic cognitive processes, most commonly spreading activation among nodes in memory (Collins \& Loftus, 1975; Neely, 1991). There are several more recent theoretical explanations (e.g., Masson, 1995; Plaut \& Booth, 2000).

Word association comes into play in semantic priming because the definition and pairing of prime-target pairs as "related" frequently has been based on word association norms. Indeed, word association norms have often yielded prime-target pairs that reveal priming effects in lexical decision and naming (for review, see Hutchison, 2003). Thus, word association seems to measure some sort of relationship that has relevance well beyond the word association task itself.
This picture, however, is complicated by a number of considerations involving the nature of the relationship uncovered in word association. This relationship may be primarily lexical (word based), semantic (e.g., categorical), conceptually based (but not categorical), or it may reflect some combination of levels. This is not a trivial issue, because the nature of the relationship assessed by both word association and semantic priming could place important limits on the utility of these tasks in research on behavior. For example, lexical associations may not have much utility beyond predicting word use, whereas conceptual or semantic relations likely imply a much broader range of relevance.

\section{The Lexical View}

Lexical associations represent co-occurrences in word use, in written or spoken language. One view is that semantic priming is not really semantic but instead involves associations only at the lexical level (Shelton \& Martin, 1992). This position is based in part on findings showing that automatic semantic priming effects are often obtained when prime-target pairs are associated on the basis of word association norms, but are less consistently obtained when prime-target pairs are related on the basis of certain semantic relations such as category coordinates (for review, see Hutchison, 2003) or similarity in the absence of association (e.g., Shelton \& Martin, 1992). This common interpretation relies heavily on the critical assumption that word association measures only lexical associations. Indeed, much of this research assumes that if word association norms, but not semantic relations, predict facilitation in lexical decision, then lexical associations must govern semantic priming. 


\section{Conceptual Associations}

In this section a concept is defined as something (e.g., a tree) that is represented in memory in, or accessible through, diverse modalities. A tree is not just the word itself (or its graphemic and phonemic linguistic representations). Memories about trees can be activated by the sight of a tree in the environment, by pictures, smells, touch, words, and related thoughts. Thus, a concept is not bound to a single perceptual modality. If words do indeed activate concepts, then it is plausible that word associations may reflect conceptual associations. Thus, tests of word association may index concept co-occurrence in everyday experience. For example, associations between tree and leaf may be detectable in word association not just because of cooccurrence in language, but also because of co-occurrence in a variety of visual experiences. A conceptual association has much more far-reaching implications for behavior than an association restricted to the lexical (word) system. For example, if semantic priming mimics activation of concepts in everyday encounters with a variety of cues differing in modality, then a semantic priming effect may provide a glimpse at concept activation processes relevant to behavior choices. Concept activation is relevant to behavior in a variety of approaches (e.g., Bargh et al., 1996), including those that address affect and behavior (Fazio, 2001).

Unfortunately, there is little evidence available to weigh the lexical association versus conceptual association views. One way to evaluate some of the necessary (but not completely sufficient) conditions of the conceptual association view is to examine associations across different modalities (e.g., words and pictures). Only a few relevant studies, however, have been conducted (Hines et al., 1986; Saffran et al., 2003).

\section{A "Pure" Semantic View \\ and Alternative Measurements}

Semantic relationships are frequently defined in terms of similarity (shared features) or category relations, but an examination of published norms reveals a variety of other meaningful relations, such as functional, script, instrument, synonym, antonym, and other relationships (Hutchison, 2003). At least one class of theory relies heavily on a similarity-based semantic model (Masson, 1995; McRae \& Boisvert, 1998). In this class of connectionist model, semantic priming is explained by the similarity between the prime and target, or more specifically, between the activation states engaged by the prime and target. A prime facilitates responses to a target to the extent that the two states match in their patterns of activation across elementary features (Masson, 1995). Despite earlier evidence from several studies showing that similarity did not produce semantic priming, MacRae and Boisvert demonstrated that similarity effects on automatic priming can be found in the absence of normative association (but see Wentura, 2000). This finding shows that association (whether lexical or conceptual) may not be the only route through which exposure to one stimulus facilitates responses to another. Affective priming is yet another route (Spruyt et al., 2004).

This work suggests that word association is not the only viable index of relation. Effects of similarity, however, are not as consistent as are effects of normative association (Hutchison, 2003; McRae \& Boisvert, 1998). In addition, similarity judgments yield a symmetric association, whereas word association can detect asymmetric relations; asymmetric relations have important empirical and theoretical manifestations (Nelson et al., 1998; see also McEvoy \& Nelson, Chapter 5). Nevertheless, similarity and 
other indexes of relationship are worthy of additional research because they do sometimes predict semantic priming in the absence of normative association and word association is certainly not immune from controversy (McRae \& Boisvert, 1998; Ratcliff \& McKoon, 1994).

\section{Mixed Association \\ and Semantic Models}

In a recent comprehensive review, Hutchison (2003) concluded that both associative and semantic processes influence semantic priming responses. This conclusion can be accommodated by a "localist" perspective (spreading activation; Collins \& Loftus, 1975) and by some distributed, connectionist models. For example, in Plaut and Booth's (2000) distributed memory model, associative effects are explained in terms of transition probabilities, in which the network learns transitions between patterns of activation through training in which one pattern follows another. In essence, the network represents habitual transitions, such that pattern A facilitates responding to pattern B to the extent that A transitioned to $\mathrm{B}$ in previous experience; this transition may constitute a predictive relationship akin to modern conceptions of a Pavlovian relation (Rescorla, 1988). Plaut and Booth's definition of a semantic effect is similar to other connectionist theories (Masson, 1995), whereby pattern A facilitates responding to $\mathrm{B}$ to the extent that the two patterns are similar in terms of shared features; that is, the network has fewer changes to make from pattern A to B. As outlined earlier, there are many additional definitions of semantic relations beyond similarity. Some of these definitions may be indistinguishable from Plaut and Booth's associative effect. For example, many functional or script relations likely involve transitions learned in the past. Plaut and Booth provide one of the few contemporary approaches to semantic priming that seems to acknowledge that the associative process could operate at the concept level (cf. Nelson et al., 1998; Spruyt et al., 2004).

Clearly, word association is still quite relevant to semantic priming research. In fact, the exact source or level of the relationship uncovered in word association may be fundamental for inferences about the nature of semantic priming and its relevance to behavior. To the extent that semantic priming effects involve automatic activation processes, associations uncovered in word association norms foretell which words or concepts more readily activate (or transition to) other words or concepts. It is not a large leap to suggest that individual differences in these associations should predict concept activation at the individual level (Stacy et al., 1997) and behavior (Stacy, 1997; Szalay et al., 1993). The authors outline some evidence for this view in a subsequent section.

\section{Conceptual Priming}

This term is usually restricted to paradigms that incorporate distinct encoding (study) and test trials. The test trials include indirect tests of memory that have been classified as conceptually driven tasks. Implicit memory research classifies word association as a conceptual test of implicit memory (Toth, 2000; Vaidya et al., 1995; Zeelenberg et al., 1999). Studies investigating word association and conceptual priming, however, vary in the extent to which their procedures explicitly evaluate the assumptions of conceptually based, implicit processing.

\section{Studies Using Amnesic \\ Patients as Participants}

Amnesic samples are relevant to inferences about implicit processing because the 
participants have deficits on direct tests of memory such as free recall. At least some assumptions about implicit versus explicit processes can be investigated because conscious recollection is impaired and clear dissociations between direct and indirect tests are revealed. Using this population, a variety of converging lines of evidence can sometimes be pieced together to make the case for a distinction in memory systems underlying different forms of memory (Ryan \& Cohen, 2003).

Several studies have shown that word association can reveal memory priming in amnesic patients. Gardner and his colleagues (1973) found that amnesic Korsakoff patients revealed significant levels of priming in word association responses to categorical cues (an indirect test of exemplar generation) following a study trial in which exemplars were matched to categories. The amnesic patients revealed significantly less memory for exemplars on direct tests (free recall and cued recall), however, than did alcoholic control participants, revealing a decrement on tests referring back to the previous study episode. Exemplar generation using word association instructions in this study provides an example of the controlled association method (Cramer, 1968), in which the set of associative responses is restricted in the instructions in some fashion (e.g., category member, verb, noun, etc.). Studies of priming in free association among amnesic patients have shown similar findings of no impairment on the indirect test (word association) and decrements on direct tests (Levy et al., 2004; Schacter, 1985; Shimamura \& Squire, 1984; Vaidya et al., 1995). Importantly, Vaidya et al.'s study demonstrated that priming in word association did not depend on perceptual match at study and test. A switch in modality from auditory during study to visual at test did not affect priming, suggesting a conceptual locus of the obtained priming effect.

\section{Studies in Normal Samples}

Several studies have focused on priming in word association using participants without memory impairments, providing information relevant to conceptual processes as well as to various associative memory parameters. For example, Zeelenberg and his colleagues (2003) manipulated the semantic context during an incidental study trial by presenting ambiguous target words within sentence contexts that were either congruent or incongruent with subsequent cue words presented during a word association test. In Experiment 2 from the same research series, a similar design was used but semantic context was varied more subtly by varying the sense of nonambiguous words. In both studies, sentence context affected priming. The authors concluded that "this finding is largely consistent with the view that priming in word association depends largely on conceptual processes" (Zeelenberg et al., 2003, p. 658). Other studies in normal samples also find significant priming effects in word association following incidental study trials, showing the predictive utility of several connection parameters that may underlie the effects (Nelson \& Goodmon, 2002; Zeelenberg et al., 1999). The values of connection parameters (e.g., association strength, associative set size) are based on word association norms, further revealing the value of association tests.

\section{Illusory Memory in Free Recall}

Deese (1959b) first found that extralist (nonstudied) intrusions on free recall of word lists could be predicted from the responses made to a critical item on word association tasks. Roediger and McDermott (1995) subsequently replicated and extended Deese's work, fostering a surge of additional research on illusory memory using what is now called the Deese-Roediger-McDermott paradigm (DRM).

Several studies using the DRM are particularly informative with respect to word 
association. McEvoy et al. (1999) manipulated associative strength based on word association norms and found that stronger preexisting connections from presented list words to the critical lures (i.e., backward associative strength) produced more false recall than weaker preexisting connection strength. Additionally, and consistent with Deese (1959b), McEvoy et al. (1999) found that stronger connectivity among the words in word lists decreased the likelihood of illusory memories. In evaluating the contribution of seven processes likely to influence false recall of critical lures, Roediger et al. (2001) found backward associative strength to be the best predictor $(r=.73)$ of false recall, consistent with Deese (1959b) and McEvoy et al. (1999). The number of list items accurately recalled was the second best predictor $(r=-.43)$ of false recall. Hicks and Hancock (2002) manipulated backward associative strength and also found that word lists with greater associative strength to the critical item were more likely to produce false recall. They attributed their findings to the strong activation of the critical item by semantic associates at encoding and not to biases at retrieval. Reich et al. (2004) showed how the DRM could be usefully applied to alcohol-related cognitions, but they focused on recognition tests that are beyond the scope of this section.

Although the exact processes underlying illusory memories revealed from the DRM are still being studied, the research reviewed here provides evidence that activation from the presented words in the word lists seem to converge on, and prime, an associatively related, but nonpresented word (or concept). The effect of associative relationship is well predicted by word association norms.

\section{Extralist Cued Recall}

In extralist cued recall, participants are prompted with cue words during testing that were not provided during a previous study trial. The test instructions are direct, asking participants to recall words from a study list. Across numerous studies, several association parameters (cue-to-target association, set size, resonance, and connectivity) have been found to be good predictors of performance in this task (for reviews and definitions, see Nelson et al., 1998; Nelson et al., 2003; Nelson et al., 1992; McEvoy \& Nelson, Chapter 5). Word association norms are used to derive the association parameters and have been found to be better predictors of extralist cued recall than have similarity tatings and word co-occurrence data (Nelson et al., in press).

Nelson and his colleagues (Nelson et al., 1998) have concluded that the effects of related associates on memory (and hence the association parameters) in extralist cued recall appear to emerge because of the implicit activation of those associates, akin to a priming effect. This view is based in part on Nelson et al.'s findings showing that associative set size effects occur regardless of the incidental or intentional nature of the study trial, regardless of whether test instructions refer to the study trial, and regardless of variations in instructions regarding guessing. Also, participants' ratings of set size do not correspond with associative set size as revealed in word association, suggesting that people's conscious cognitions about this process are independent from the apparently implicit process proposed by Nelson et al. On the basis of these and a number of related findings, Nelson and his colleagues assume the coexistence of independent implicit and explicit representations in memory, advanced in their theory of Processing Implicit and Explicit Representations, PIER1 and PIER2 (McEvoy \& Nelson, Chapter 5; Nelson et al., 1998; Nelson et al., 1992). This theory also provides a viable explanation of findings in recognition (e.g., Nelson et al., 2003; Nelson et al., 1998), as well as results addressed earlier from conceptual 
priming in free association (Nelson \& Goodmon, 2002) and illusory memory (McEvoy et al., 1999). In an analysis of associative parameters from over 29 controlled experimental studies, propositions from PIER2 fared better than did spreading activation (Nelson et al., 2003).

\section{Summary of Basic \\ Cognitive Research}

Results from a variety of contemporary paradigms using word association norms, as well as earlier research, provide a remarkable empirical consensus of the utility of this simple test in basic cognitive research. It is a challenge to cognitive research to uncover an index of relation that is a better predictor of a wide variety of cognitive responses (cf. Nelson et al., 1998). Yet, there are a number of questions about the exact processes engaged in word association itself, as addressed in subsequent sections. The nature of these processes may be critical to addictive behaviors, contextual effects on these behaviors (Krank \& Wall, Chapter 19), and interpretations of implicit processes.

\section{APPLICATION AND \\ PREDICTIVE UTILITY IN RESEARCH ON HEALTH BEHAVIOR}

\section{Examples of Assessment Strategies in Drug-Use Research}

Variations of word association methods virtually identical to methods from basic cognitive research have been used in research on drug use and other health behaviors. Szalay and colleagues (e.g., Szalay et al., 1999) adapted the continued association methods of Noble (1952) to study the spontaneous distribution of continued free associations in drug users. With continued free associations, multiple (single-word) responses are obtained for the same cue, which is repeated in a column format (e.g., fun: ; fun: ; fun: ). A variety of salient cues are offered as prompts. We have used an alternative, free-association method (Stacy, Ames, et al., 1996) that requires participants to write down the first word that comes to mind to single occurrences of each word in a list of different ambiguous cue words (e.g., fun: ; draft: — "drunk") are binary coded (0 or 1) for consistency with the target behavior (e.g., alcohol use) and summed to form a scale used as a predictor of the behavior. We also have used controlled associations (Cramer, 1968), in which the potential set size of responses is restricted to a form of verb generation. With this task, participants are asked to write down the first behavior or action that comes to mind in response to one or several words (e.g., having fun: __ ). There is preliminary evidence that priming in verb generation tasks is intact in amnesic patients (Seger et al., 1997) and measures an implicit, conceptual form of memory (Seger et al., 1999), but the support for free association is much broader. Pros and cons of free, controlled, and continuous association and measurement suggestions for applied work have been outlined previously (Stacy, Ames, \& Leigh, 2004). Such indirect assessments, when not mentioning any particular behavior or encouraging recollection, seem likely to minimize self-perception processes and other executive or explicit-process effects on associative responses.

\section{Summary of Drug-Abuse Findings}

In previous research, we have argued that responses to word associations reflect associations in memory between cues, behaviors, and outcomes, and that these associations bias behavior decisions in a relatively spontaneous, possibly implicit manner (Ames \& Stacy, 1998; Stacy, 1997). Szalay 
and his colleagues have advocated an essentially similar focus on the spontaneous effect of meaningful associations on drug use, as well as indirect assessment through word association (e.g., Szalay et al., 1999). Over a dozen studies provide evidence for the effectiveness of word association tasks as predictors of alcohol use, marijuana use, or HIV-risk behavior in diverse populations (for reviews, see Stacy, Ames, \& Leigh, 2004; Szalay et al., 1999), and some of this research controls for potential confounders and moderators (e.g., ethnicity, gender, acculturation, sensation seeking, outcome expectancies) in the analysis (e.g., Palfai \& Wood, 2001; Stacy, 1997). An updated review of much of this literature is provided by Ames et al. (Chapter 23). Overall, there is substantial empirical support for the utility of word association responses in predicting drug use.

\section{Other Open-Ended \\ Cognitive Tests Applicable to Health Behavior}

Other open-ended tests applicable to health behavior share some similarities to word association. To our knowledge, however, most of these have not been used to predict responses in paradigms implicated in automatic or implicit processes (e.g., semantic priming, extralist cued recall). These other open-ended procedures include, for example, a variety of thought listing and think-aloud techniques used to infer chronic accessibility in social cognition (Bargh et al., 1986; Higgins et al., 1982), situation-specific cognitions that may inform therapeutic trials (Davison et al., 1997), and processes involved in coping (Cacioppo et al., 1997). A variation of this class of test asks participants to list how people feel when they engage in the behavior (Dunn \& Goldman, 2000) or what outcomes of the behavior first come to mind (Stacy, Galaif, et al., 1996). Several other variations akin to word association have proven to be empirically useful, as revealed by Goldman et al. (Chapter 8 ).

\section{BENEFITS AND LIMITATIONS}

\section{Limits of Inference}

Norms from word association predict apparently automatic or implicit processes in a variety of paradigms. Word association tests have been used successfully as indirect tests of conceptual priming, providing good evidence of functional properties that diverge from direct tests. Individual differences in word association responses predict behavior, consistent with some theories of implicit cognition. Although word association studies on drug use have relied on previously ascertained functional properties of these measures, no single study on drug use has itself fully examined properties that characterize implicit or automatic processes. Some guidelines are now available to improve future research in this area (De Houwer, Chapter 2).

One sense of implicit cognition, pervasive in research on implicit memory, focuses on responses in the absence of deliberate, conscious recollection of an event. Research reviewed earlier suggests that systematic word association responses can occur in the absence of these recollective processes though the findings do not imply that conscious, deliberate recollection never occurs. Another possibility is that although conscious recollection of an event is not engaged, processes other than an implicit association affect the response. One example of such a process is filtering (editing, censoring), which has been addressed only minimally in previous research (Stacy et al., 1997). If this threat increases Type I error, however, then it must involve a confounding relationship rather than random error. Some, but not all, potential confounders, such as personality (sensation seeking), habit, gender, acculturation, and 
outcome expectancies have been addressed in health-behavior research.

Conscious awareness of activated content, which characterizes word association responses, is different than deliberate or conscious recollection of the source of that content. Conscious awareness of content also does not imply that introspections about one's behavior affected that content. In a variety of findings from implicit memory research, including some research on word association (e.g., Vaidya et al., 1995), content can reach consciousness or awareness, the response can take some time, but the origins of the content are not known or identified by the participant. This presumed functional quality should be further investigated in drug-use research.

\section{Relative Cognition}

Word association is one of the few measures of cognition capable of assessing target cognitions in competition with a large number of alternatives. This is because the response format leads to self-generation of responses that could be almost anything-a potentially vast set size (Nelson et al., 1998) or "fan" (Anderson, 1983) of alternatives. The importance of relative cognition and alternatives is emphasized in areas as diverse as advertising (Stacy, Pearce, et al., 2004; Stewart, 1989), traditional social learning theory (Rotter, 1954), and motivational theory (Cox et al., Chapter 17; Palfai, Chapter 26). Further, a number of models of memory instantiate memory competition, whether conceived of as an automatic or explicit form of memory. Yet, if alternatives are examined at all, most other indirect tests and direct tests of health-related cognitions do not evaluate cognitive responses to more than one or several alternatives. Word association, on the other hand, allows the investigator to study associations involving the "target" behavior or content of focus in comparison to all other possibilities, even though the alternatives are not explicitly mentioned. One might expect this to be a hopeless method, given that so many responses are possible. Nevertheless, the reviewed data support the view that something quite systematic is revealed in these tests.

\section{Context and Larger \\ Patterns of Association}

Word association tests can be used to study context effects (Krank \& Wall, Chapter 19). "Local" context effects, within the test itself, can be manipulated by varying the number and nature of cue words or by manipulating preceding items or the imagined context immediately before the requested associative response (Stacy et al., 1994; Stacy et al., 1997). Since everyday cognition is unlikely to be devoid of context, the study of local context effects in indirect tests of all types may improve the generalizability, and possibly predictive utility, of these tests. The manipulation of local context can also benefit the study of configural relations (Dosher \& Rosedale, 1997). It is an empirical question whether local context, that is, context most likely to be processed in conjunction with the test item (e.g., an adjacent word), is more or less important than the global environmental context of the test, which may or may not be processed in a manner that affects test responses.

Another benefit of word association is that it can reveal a large pattern of connection across many concepts, and such larger patterns may be more important to behavior than one or several associations in isolation. A pattern of connection is particularly relevant to such theories as PIER2 (Nelson et al., 1998; McEvoy \& Nelson, Chapter 5), Hopfield networks (e.g., Masson, 1995), and connectionist theories applied to social behavior (Smith \& DeCoster, 1998). For example, results from studies on PIER2 
show that parameters (such as resonance, connectivity, and set size) involving many associates of a target concept are important for activation of a target concept in memory, even when those associates are not presented during a study or test trial (Nelson et al., 2003; Nelson et al., 1998). It is conceivable that individual differences in connection patterns precede and predict experimentation with drugs and change further once drugs are tried. The study of patterns of association and activation across a fairly large number of elements is a different approach than the study of only several associations studied in isolation (e.g., only those that might represent expectancy for reinforcement).

Finally, associations, including larger patterns, revealed by word association tests are not applied in a theoretical vacuum. A number of theories are available to explain the development or learning of associations revealed by these tests, ranging from simple Hebbian learning rules applied to some connectionist networks (Masson, 1995) to multiple-trace explanations of associative memory (Hintzman, 1986). These approaches can be readily applied to associations involving affect or motivation as well as nonemotional concepts and have been useful in explaining drug use (Stacy, 1995).

\section{Prevention and}

\section{Treatment Interventions}

Beginning with the work of Szalay and his colleagues, several investigators have provided guidelines for assessment of drug-use intervention effects through the study of word association (Stacy, Ames, \& Leigh, 2004; Szalay et al., 1993; Szalay et al., 1999). The basic idea is that word association may reflect a change in associations, or creation of new associations, following an intervention. In some theories of implicit memory, such as dissociation and distinct representation models (for review, see Moscovitch, 2000), new associations could affect behavior because they operate through implicit representations that do not require the participant to deliberately or consciously think back to previously learned information from a program-something people may not do very often. Implicitly activated cognitions would influence related behaviors, just as they influence related $\operatorname{cog}$ nitions in models of implicit activation (Nelson et al., 1998); some assumptions from this view are consistent with theories arguing for biasing effects of memory activation on social behavior and judgment (e.g., Bargh et al., 1986; Fazio et al., 1986).

An alternative view, consistent with transfer appropriate processing (Morris et al., 1977; Roediger et al., 2002), focuses on the consistency of modes of processing across encoding and test trials. Much of value in what is learned in an intervention may not involve deliberate memorization processes but rather elaborations of new conjunctions of information. These elaborations may influence associations in memory, potentially one of the most active ingredients of the intervention (Stacy, Ames, \& Knowlton, 2004). Tests of association, rather than tests of deliberate recollection or self-reflection, are likely more compatible with processes that strengthen associations. Further, tests of implicit conceptual memory, such as word association, may more closely reflect the type of spontaneous activation process engaged in everyday situations. If an intervention influences these tests, it might more readily transfer, influencing behavior in a relatively spontaneous manner. Word association may, in James's (1913, p. 257) terminology, capture "spontaneous trains of thought."

\section{CONCLUSIONS}

Word association tests clearly assess some type of association in memory relevant to a variety of cognitive responses and behaviors. 
Associations derived from these assessments appear to operate at least relatively spontaneously on other cognitive responses. In a few paradigms using these tests, inferences of implicit processes are difficult to rule out. Many of the findings are indicative, though not conclusive, of a concept activation process. A number of theories of social cognition (Bargh et al., 1986; Fazio, 2001; Smith, 1996) and health behavior (chapters in this book) suggest that concept activation and its affective counterparts influence behavior. If associations uncovered in word association affect behavior, then their value is affirmed despite some current uncertainty about the exact nature of the association. Nevertheless, more research is needed to fully understand the properties of this test under different assessment conditions.

The degree of convergence from multiple lines of evidence regarding word association across divergent, independent paradigms is quite rare in cognitive research relevant to health behavior: these findings should not be ignored. Yet, potential confounders of word association also must be acknowledged. Overall, it is a challenge for cognitive research to provide evidence of a more generally useful, and less controvertible, test of association in cognition.

\section{REFERENCES}

Ames, S. L., \& Stacy, A. W. (1998). Implicit cognition in the prediction of substance use among drug offenders. Psychology of Addictive Behaviors, 12(4), 272-281.

Anderson, J. R. (1983). The architecture of cognition. Cambridge, MA: Harvard University Press.

Bargh, J. A., Bond, R. N., Lombardi, W. J., \& Tota, M. E. (1986). The additive nature of chronic and temporary sources of construct accessibility. Journal of Personality and Social Psychology, 50(5), 869-878.

Bargh, J. A., Chen, M., \& Burrows, L. (1996). Automaticity of social behavior: Direct effects of trait construct and stereotype activation on action. Journal of Personality and Social Psychology, 71(2), 230-244.

Bechtel, W., \& Abrahamsen, A. (2002). Connectionism and the mind: Parallel processing, dynamics, and evolution in networks ( 2 nd ed.). Malden, MA: Blackwell.

Boring, E. G. (1950). A history of experimental psychology (2nd ed.). New York: Appleton-Century-Crofts.

Cacioppo, J. T., von Hippel, W., \& Ernst, J. M. (1997). Mapping cognitive structures and processes through verbal content: The thought-listing technique. Journal of Consulting and Clinical Psychology, 65(6), 928-940.

Cattell, J. M., \& Bryant, S. (1889). Mental association investigated by experiment. Mind, 14, 230-250.

Collins, A. M., \& Loftus, E. F. (1975). A spreading-activation theory of semantic processing. Psychological Review, 82(6), 407-428.

Cook, S. W., \& Skinner, B. F. (1939). Some factors influencing the distribution of associated words. Psychological Record, 3, 178-184.

Cramer, P. (1968). Word association. New York: Academic Press.

Crovitz, H. F. (1970). Galton's walk: Methods for the analysis of thinking, intelligence, and creativity. Oxford, UK: Harper \& Row.

Davison, G. C., Vogel, R. S., \& Coffman, S. G. (1997). Think-aloud approaches to cognitive assessment and the articulated thoughts in simulated situations paradigm. Journal of Consulting and Clinical Psychology, 65(6), 950-958. 
Dawson, M. R. W. (2004). Minds and machines: Connectionism and psychological modeling. Malden, MA: Blackwell.

Deese, J. (1959a). Influence of inter-item associative strength upon immediate free recall. Psychological Reports, 5, 305-312.

Deese, J. (1959b). On the prediction of occurrence of particular verbal intrusions in immediate recall. Journal of Experimental Psychology, 58, 17-22.

Dosher, B. A., \& Rosedale, G. S. (1997). Configural processing in memory retrieval: Multiple cues and ensemble representations. Cognitive Psychology, 33(3), 209-265.

Dunn, M. E., \& Goldman, M. S. (2000). Drinking-related differences in expectancies of children assessed as first associates. Alcoholism: Clinical and Experimental Research, 24(11), 1639-1646.

Fazio, R. H. (2001). On the automatic activation of associated evaluations: An overview. Cognition \& Emotion, 15(2), 115-141.

Fazio, R. H., Sanbonmatsu, D. M., Powell, M. C., \& Kardes, F. R. (1986). On the automatic activation of attitudes. Journal of Personality and Social Psychology, $50(2), 229-238$.

Freud, S. (1995). The Freud reader. New York: Norton.

Gardner, H., Boller, F., Moreines, J., \& Butters, N. (1973). Retrieving information from Korsakoff patients: Effects of categorical cues and reference to the task. Cortex, 9(2), 165-175.

Hicks, J. L., \& Hancock, T. W. (2002). Backward associative strength determines source attributions given to false memories. Psychonomic Bulletin \& Review, 9(4), 807-815.

Higgins, E. T., King, G. A., \& Mavin, G. H. (1982). Individual construct accessibility and subjective impressions and recall. Journal of Personality and Social Psychology, 43(1), 35-47.

Hines, D., Czerwinski, M., Sawyer, P. K., \& Dwyer, M. (1986). Automatic semantic priming: Effect of category exemplar level and word association level. Journal of Experimental Psychology: Human Perception and Performance, 12(3), 370-379.

Hintzman, D. L. (1986). "Schema abstraction" in a multiple-trace memory model. Psychological Review, 93(4), 411-428.

Hutchison, K. A. (2003). Is semantic priming due to association strength or feature overlap? A microanalytic review. Psychonomic Bulletin \& Review, 10(4), 785-813.

James, W. (1913). Psychology. New York: Henry Holt.

Jung, C. G. (1910). The association method. American Journal of Psychology, 21(2), 219-269.

Levy, D. A., Stark, C. E. L., \& Squire, L. R. (2004). Intact conceptual priming in the absence of declarative memory. Psychological Science, 15, 680-686.

Masson, M. E. J. (1995). A distributed memory model of semantic priming. Journal of Experimental Psychology: Learning, Memory, and Cognition, 21(1), 3-23.

McEvoy, C. L., Nelson, D. L., \& Komatsu, T. (1999). What is the connection between true and false memories? The differential roles of interitem associations in recall and recognition. Journal of Experimental Psychology: Learning, Memory, and Cognition, 25(5), 1177-1194.

McRae, K., \& Boisvert, S. (1998). Automatic semantic similarity priming. Journal of Experimental Psychology: Learning, Memory, and Cognition, 24(3), 558-572.

Morris, C. D., Bransford, J. D., \& Franks, J. J. (1977). Levels of processing versus transfer appropriate processing. Journal of Verbal Learning and Verbal Behavior, 16(5), 519-533. 
Moscovitch, M. (2000). Theories of memory and consciousness. In E. Tulving \& F. I. M. Craik (Eds.), The Oxford handbook of memory (pp. 609-625). London: Oxford University Press.

Neely, J. H. (1991). Semantic priming effects in visual word recognition: A selective review of current findings and theories. In D. Besner \& G. W. Humphreys (Eds.), Basic processes in reading: Visual word recognition (pp. 264-336). Hillsdale, NJ: Lawrence Erlbaum.

Nelson, D. L., Drydal, G. M., \& Goodmon, L. B. (in press). What is pre-existing strength? Predicting free association probabilities, similarity ratings, and cued recall probabilities. Psychonomic Bulletin of Review.

Nelson, D. L., \& Goodmon, L. B. (2002). Experiencing a word can prime its accessibility and its associative connections to related words. Memory \& Cognition, 30(3), 380-398.

Nelson, D. L., McEvoy, C. L., \& Pointer, L. (2003). Spreading activation or spooky action at a distance? Journal of Experimental Psychology: Learning, Memory, and Cognition, 29, 42-52.

Nelson, D. L., McKinney, V. M., Gee, N. R., \& Janczura, G. A. (1998). Interpreting the influence of implicitly activated memories on recall and recognition. Psychological Review, 105, 299-324.

Nelson, D. L., Schreiber, T. A., \& McEvoy, C. L. (1992). Processing implicit and explicit representations. Psychological Review, 99(2), 322-348.

Noble, C. E. (1952). An analysis of meaning. Psychological Review, 49, 421-430.

Palfai, T. P., \& Wood, M. D. (2001). Positive alcohol expectancies and drinking behavior: The influence of expectancy strength and memory accessibility. Psychology of Addictive Behaviors, 15(1), 60-67.

Plaut, D. C., \& Booth, J. R. (2000). Individual and developmental differences in semantic priming: Empirical and computational support for a single-mechanism account of lexical processing. Psychological Review, 107(4), 786-823.

Preece, P. F. W. (1978). Three-year stability of certain word-association indices. Psychological Reports, 42, 25-26.

Ratcliff, R., \& McKoon, G. (1994). Retrieving information from memory: Spreading-activation theories versus compound-cue theories. Psychological Review, 101(1), 177-184.

Reich, R. R., Goldman, M. S., \& Noll, J. A. (2004). Using the false memory paradigm to test two key elements of alcohol expectancy theory. Experimental \& Clinical Psychopharmacology, 12(2), 102-110. .

Rescorla, R. A. (1988). Pavlovian conditioning. It's not what you think it is. American Psychologist, 43(3), 151-160.

Roediger, H. L., Gallo, D. A., \& Geraci, L. (2002). Processing approaches to cognition: The impetus from the levels-of-processing framework. Memory, 10(5-6), 319-332.

Roediger, H. L., \& McDermott, K. B. (1995). Creating false memories: Remembering words not presented in lists. Journal of Experimental Psychology: Learning, Memory, and Cognition, 21(4), 803-814.

Roediger, H. L., Watson, J. M., McDermott, K. B., \& Gallo, D. A. (2001). Factors that determine false recall: A multiple regression analysis. Psychonomic Bulletin o Review, 8(3), 385-407.

Rotter, J. B. (1954). Social learning and clinical psychology. Oxford, UK: Prentice Hall. Ryan, J. D., \& Cohen, N. J. (2003). Evaluating the neuropsychological dissociation evidence for multiple memory systems. Cognitive, Affective \& Behavioral Neuroscience, 3(3), 168-185. 
Saffran, E. M., Coslett, H. B., \& Keener, M. T. (2003). Differences in word associations to pictures and words. Neuropsychologia, 41(11), 1541-1546.

Schacter, D. L. (1985). Priming of old and new knowledge in amnesic patients and normal subjects. Annals of the New York Academy of Sciences, 444, 41-53.

Seger, C. A., Rabin, L. A., Desmond, J. E., \& Gabrieli, J. D. E. (1999). Verb generation priming involves conceptual implicit memory. Brain and Cognition, $41(2), 150-177$.

Seger, C. A., Rabin, L. A., Zarella, M., \& Gabrieli, J. D. E. (1997). Preserved verb generation priming in global amnesia. Neuropsychologia, 35(8), 1069-1074.

Shelton, J. R., \& Martin, R. C. (1992). How semantic is automatic semantic priming? Journal of Experimental Psychology: Learning, Memory, and Cognition, 18(6), 1191-1210.

Shimamura, A. P., \& Squire, L. R. (1984). Paired-associate learning and priming effects in amnesia: A neuropsychological study. Journal of Experimental Psychology: General, 113(4), 556-570.

Smith, E. R. (1996). What do connectionism and social psychology offer each other? Journal of Personality and Social Psychology, 70(5), 893-912.

Smith, E. R., \& DeCoster, J. (1998). Knowledge acquisition, accessibility, and use in person perception and stereotyping: Simulation with a recurrent connectionist network. Journal of Personality and Social Psychology, 74(1), 21-35.

Spruyt, A., Hermans, D., De Houwer, J., \& Eelen, P. (2004). Automatic nonassociative semantic priming: Episodic affective priming of naming responses. Acta Psychologica, 116(1), 39-54.

Stacy, A. W. (1995). Memory association and ambiguous cues in models of alcohol and marijuana use. Experimental of Clinical Psychopharmacology, 3(2), 183-194.

Stacy, A. W. (1997). Memory activation and expectancy as prospective predictors of alcohol and marijuana use. Journal of Abnormal Psychology, 106(1), 61-73.

Stacy, A. W., Ames, S. L., \& Knowlton, B. J. (2004). Neurologically plausible distinctions in cognition relevant to drug use etiology and prevention. Substance Use of Misuse, 39, 1571-1623.

Stacy, A. W., Ames, S. L., \& Leigh, B. C. (2004). An implicit cognition assessment aproach to relapse, secondary prevention, and media effects. Cognitive and Behavioral Practice, 11, 139-149.

Stacy, A. W., Ames, S. L., Sussman, S., \& Dent, C. W. (1996). Implicit cognition in adolescent drug use. Psychology of Addictive Behaviors, 10(3), 190-203.

Stacy, A. W., Galaif, E. R., Sussman, S., \& Dent, C. W. (1996). Self-generated drug outcomes in high-risk adolescents. Psychology of Addictive Behaviors, 10(1), $18-27$.

Stacy, A. W., Leigh, B. C., \& Weingardt, K. R. (1993, November). An individualdifference perspective applied to normative associative strength. Paper presented at the annual meeting of the Psychonomic Society, Washington, DC.

Stacy, A. W., Leigh, B. C., \& Weingardt, K. R. (1994). Memory accessibility and association of alcohol use and its positive outcomes. Experimental 6 Clinical Psychopharmacology, 2(3), 269-282.

Stacy, A. W., Leigh, B. C., \& Weingardt, K. R. (1997). An individual-difference perspective applied to word association. Personality and Social Psychology Bulletin, 23(3), 229-237.

Stacy, A. W., Pearce, S. G., Zogg, J. B., Unger, J. B., \& Dent, C. W. (2004). A nonverbal test of naturalistic memory for alcohol commercials. Psychology \& Marketing, 21(4), 295-322. 
Stewart, D. W. (1989). Measures, methods, and models in advertising research. Journal of Advertising Research, 29(3), 54-60.

Szalay, L. B., Carroll, J. F. X., \& Tims, F. (1993). Rediscovering free associations for use in psychotherapy. Psychotherapy: Theory, Research, Practice, Training, $30(2), 344-356$.

Szalay, L. B., Strohl, J. B., \& Doherty, K. T. (1999). Psychoenvironmental forces in substance abuse prevention. Dordrecht, The Netherlands: Kluwer Academic.

Szalay, L. B., Windle, C., \& Lysne, D. A. (1970). Atritude measurement by free verbal associations. Journal of Social Psychology, 82(1), 43-55.

Thorne, B. M., \& Henley, T. B. (2001). Connections in the history and systems of psychology (2nd ed.). Boston: Houghton Mifflin.

Toth, J. P. (2000). Nonconscious forms of human memory. In E. Tulving \& F. I. M. Craik (Eds.), The Oxford handbook of memory (pp. 245-261). London: Oxford University Press.

Underwood, B. J. (1965). False recognition produced by implicit verbal responses. Journal of Experimental Psychology, 70(1), 122-129.

Vaidya, C. J., Gabrieli, J. D. E., Keane, M. M., \& Monti, L. A. (1995). Perceptual and conceptual memory processes in global amnesia. Neuropsychology, 9(4), 12.

Wentura, D. (2000). Dissociative affective and associative priming effects in the lexical decision task: Yes versus no responses to word targets reveal evaluative judgment tendencies. Journal of Experimental Psychology: Learning, Memory, and Cognition, 26(2), 456-469.

Woodworth, R. S. (1921). Psychology: A study of mental life. New York: Henry Holt.

Zeelenberg, R., Pecher, D., Shiffrin, R. M., \& Raaijmakers, J. G. W. (2003). Semantic context effects and priming in word association. Psychonomic Bulletin o Review, 10(3), 653-660.

Zeelenberg, R., Shiffrin, R. M., \& Raaijmakers, J. G. W. (1999). Priming in a free association task as a function of association directionality. Memory \& Cognition, $27(6), 956-961$. 